\title{
PERILAKU PENGGUNAAN INTERNET BANKING SEBAGAI ALAT TRANSAKSI FINANSIAL
}

\author{
BEHAVIORAL USAGE OF INTERNET BANKING AS FINANCIAL TRANSACTION TOOL
}

\author{
Intan Ika Putri Heryani ${ }^{* 1}$, Megawati Simanjuntak ${ }^{* *}$, dan Agus Maulana $\left.{ }^{* * *}\right)$ \\ *) Sekolah Bisnis, IPB University \\ Gedung SB IPB, Jalan Padjajaran, Bogor, Indonesia 16151 \\ ${ }^{* *}$ Departemen Ilmu Keluarga dan Konsumen, Fakultas Ekologi Manusia, IPB University \\ J1. Lingkar Kampus IPB Dramaga, Bogor 16680 \\ $\left.{ }^{* * *}\right)$ Universitas Dr. Sutomo \\ J1. Semmolowaru No. 84, Surabaya, Jawa Timur 6011
}

\begin{abstract}
Internet banking is one of the bank services to do financial and non-financial transactions via an internet network. Internet banking provides consumers' benefits such as fast, safe, convenient, and inexpensive transactions. Moreover, the bank gains business expansion and customer loyalty as their own benefits. Internet banking usage is influenced by perceived usefulness, perceived ease of use, visibility, enjoyment, social influences, attitude toward using, behavioral intention, and actual usage. The study's purpose was to analyze these variables and formulate managerial implications in developing internet banking for the future. The study approach used the Technology Acceptance Model (TAM), which was tested by Structural Equation Modeling (SEM). The results showed five-factor relationships. First, the perceived ease of use had a significant influence on perceived usefulness. Second, the perceived usefulness was a significant toward the behavioral intention. Third, visibility and enjoyment had significant influence on attitude toward using. Fourth, the attitude toward using had significantly influenced behavioral intention. Five, the behavioral intention had significant toward actual usage. While the variable of visibility and enjoyment indirectly affected the actual usage.
\end{abstract}

Keywords: internet banking, perceived ease of use, perceived usefulness, behavioural intention, visibility

\begin{abstract}
Abstrak: Internet banking merupakan salah satu bentuk layanan perbankan kepada nasabah untuk melakukan transaksi perbankan seperti transaksi finansial dan nonfinansial melalui jaringan internet. Internat banking dapat memberikan keuntungan bagi nasabah berupa layanan perbankan yang cepat, aman, nyaman, dan murah, sementara dari segi perusahaan dapat memberikan manfaat seperti perluasan usah dan, kesetiaan pelanggan. Beberapa variabel yang mempengaruhi penggunaan internet banking diantaranya, yaitu perceived usefulness, perceived ease of use, visibility, enjoyment, social influent, attitude toward using, behavioral intention, dan actual usage. Tujuan dari penelitian ini adalah untuk menganalisis variabel tersebut dan merumuskan implikasi manajerial yang dapat diterapkan dalam mengembangkan internet banking untuk perusahaan. Penelitian menggunakan pendekatan Technology Acceptance Model (TAM) dengan uji statistik menggunakan teknik Structural Equation Modelling (SEM). Hasil penelitian menunjukkan perceived ease of use berpengaruh signifikan terhadap perceived usefulness, perceived usefulness berpengaruh signifikan terhadap behavioral intention, visibility dan enjoyment berpengaruh signifikan terhadap attitude toward using, attitude toward using berpengaruh signifikan terhadap behavioral intention dan behavioral intenton berpengaruh signifikan terhadap actual usage. Variabel visibility dan enjoyment secara tidak langsung berpengaruh terhadap actual usage.
\end{abstract}

Kata kunci: internet banking, perspektif kemudahan pengaplikasian, perspektif penggunaan, niat berperilaku, visibilitas

${ }^{1}$ Corresponding author:

Email: intanika.hp@mail.com 


\section{PENDAHULUAN}

Sejalan dengan perkembangan teknologi, penggunaan layanan internet oleh masyarakat juga turut meningkat. Akan tetapi penggunaan layanan internet sebagian besar digunakan untuk jenis layanan cahting, sementara untuk penggunaan layanan perbankan masih memiliki porsi yang kecil. Salah satu layanan perbankan yang menggunakan layanan internet adalah interent banking. Internet banking menjadi salah satu bentuk layanan digital kepada nasabah.

Jenis transaksi internet banking dibagi menjadi dua, yaitu transaksi finansial dan nonfinansial. Menu transaksi finansial yang dapat diakses oleh nasabah diantaranya seperti mentransfer dana, membayar listrik, membayar e-commerce, membeli tiket pesawat dan lain-lain. Sementara untuk menu transaksi nonfinansial diantaranya seperti mengecek saldo serta melihat mutasi rekening. Dengan adanya layanan digital tersebut maka nasabah mendapatkan keuntungan dari segi waktu dan biaya karena nasabah dapat melakukan transaksi kapan saja dan dimana pun selama terhibung dengan internet. Dengan demikian maka nasabah tidak perlu datang ke cabang sehingga dapat menghemat waktu serta biaya perjalanan. Sementara itu, manfaat yang diharapkan oleh bank diantaranya adalah dapat memberikan costomer loyalty, revenue and cost improvement, serta diharapkan dapat memberikan suatu model bisnis baru yang dapat ditawarkan oleh bank kepada nasabah. Dengan manfaat yang diperoleh oleh bank, maka peningkatan penggunaan internet banking oleh nasabah Bank XYZ harus ditingkatkan.

Yang akan menjadi objek pada penelitian ini adalah internet banking Bank XYZ. Hal ini dikarenakan Bank XYZ merupakan bank Indonesia pertama yang menerapkan internet banking secara massive. Bank XYZ mencoba untuk menawarkan segala bentuk layanan kepada nasabah untuk menfasilitasi seluruh kebutuhan transaksi nasabah. Akan tetapi, jumlah pengguna internet banking, khususnya Bank XYZ saat ini masih jauh dari target yang diharapkan, yaitu kurang dari $50 \%$.

Penelitian mengenai internet banking sudah pernah dilakukan oleh beberapa peneliti lain. Berdasarkan penelitian yang telah dilakukan oleh Poon (2008), kenyamanan menjadi salah satu faktor yang dapat memengaruhi nasabah dalam menggunakan internet banking. Penelitian lain yang telah dilakukan oleh Zaithaml (2013) menjelaskan bahwa accessilability atau kemampuan untuk mengakses memberikan pengaruh yang penting kepada nasabah untuk menggunakan internet banking. Akan tetapi walaupun dapat dengan mudah digunakan, faktor keamanan harus tetap diperhatikan. Feature atau fitur merupakan bagian penting yang dapat menarik nasabah untuk menggunakan internet banking, semakin bermacam serta baik fungsinya dianggap dapat meningkatkan penggunaan internet banking (Gerrad dan Cuningham, 2003). Fees and charges merupakan ukuran biaya atas penggunaan dari suatu jasa, hal ini dianggap penting karena nasabah tetap mengharapkan biaya yang lebih rendah dalam setiap layanan di internet banking tersebut (Lee dan Lee, 2011). Bank reputation atau reputasi bank merupakan bagian penting yang dapat memberikan keyakinan nasabah untuk mengunakan jasa layanan internet banking. Aaker dan Keller (1990) menjelaskan bahwa pertimbangan nasabah dalam menggunakan jasa bank sangat terkait dengan reputasi bank tersebut. Penelitian lain terhadap internet banking juga dilakukan oleh Yudha dan Isgiyarta (2015) menjelaskan bahwa faktor-faktor yang berpengaruh positif terhadap pengguna internet banking adalah perceived of usefulness, perceived ease of use, dan perceived trust.

Peneliti mengadopsi pendekatan Technology Acceptance Model (TAM) dengan uji statistik menggunakan teknik Structural Equation Modeling (SEM) untuk mengidentifikasi faktor-faktor penyebabnya, sehingga manajemen dapat merumuskan strategi untuk meningkatkan penggunaan internet banking. Penelitian ini dilakukan untuk menganalisa variabel-variabel yang memengaruhi penggunaan internet banking. Berdasarkan penelitian yang telah dilakukan sebelumnya, adapun variabel-variabel yang akan dianalisis, yakni perceived ease of use, perceived usefulness, visibility, enjoyment, social influence, attitude toward using, behavoral intention dan actual usage. Selain menganalisis variabel-variabel yang memengaruhi penggunaan internet banking, penelitian ini juga diharapkan dapat merumuskan implikasi manajerial yang dapat diterapkan dalam mengembangkan internet banking dikemudian hari. 


\section{METODE PENELITIAN}

Penelitian dilakukan pada rentang waktu September 2018 sampai dengan November 2018. Data yang digunakan merupakan data primer dari kuesioner yang telah disebarkan melalui email dan aplikasi pengirim pesan. Responden dapat langsung mengisi kuesiner menggunakan google-form (self-administer). Jumlah sampel sebanyak 130 responden dengan kriteria merupakan nasabah Bank XYZ yang telah menggunakan internet banking minimal selama 6 bulan. Skala yang digunakan merupakan skala interval dengan pendekatan skala likert untuk mengukur sikap.

Berdasarkan penelitian yang telah dilakukan oleh Kurnia et al. (2006), variabel yang memengaruhi penggunaan internet banking diantaranya adalah perceived usefulness, perceived ease of use, visibilit, social influence, attitude toward using, behaioral intention. Sedangkan berdasarkan penelitian yang telah dilakukan oleh Santoso (2012), variabel yang memengaruhi attitude toward using salah satunya adalah enjoyment. Berdasarkan kedua penelitian tersebut maka kerangka model pemikiran yang dibentuk adalah seperti pada Gambar 1.

Actual usage secara langsung dipengaruhi oleh behavioral intention. Selain itu, actual usage secara tidak langsung dipengaruhi oleh attitude toward using, perceived usefulness, perceived ease of use, social influence, enjoyment, dan visibility melalui behavioral intention. Variabel behavioral intention secara langsung dipengaruhi oleh attitude toward using dan perceived usefulness. Variabel attitude toward using secara langsung dipengaruhi oleh social influence, enjoyment, visibility, perceived usefulness dan perceived ease of use. Sementara itu variabel perceived ease of use juga turut memengaruhi variabel perceived usefulness. Dengan demikian, maka hipostesis dalam penelitian ini menjadi:

H1 : Perceived ease of use berpengaruh terhadap attitude toward using

H2 : Perceived ease of use berpengaruh terhadap perceived usefulness

H3 : Perceived usefulness berpengaruh terhadap attitude toward using

H4 : Perceived usefulness berpengaruh terhadap behavioral intention

H5 : Visibility berpengaruh terhadap attitude toward using
H6 : Enjoyment berpengaruh terhadap attitude toward using

H7 : Social influence berpengaruh terhadap atitude toward using

H8 : Attitude toward using berpengaruh terhadap behavioral intention

H9 : Behavioral intention berpengaruh terhadap actual usage

Hipotesis tersebut didukung oleh beberapa penelitian yang telah dilakukan sebelumnya. Berdasarkan hasil uji hipotesis yang dilakukan oleh Adhiputra (2015), perceived ease of use berpengaruh positif terhadap attitude toward using, selain itu pada penelitian tersebut juga mendapatkan hasil bahwa perceived usefulness berpengaruh terhadap attitude toward using. Penelitian serupa juga dilakukan oleh Santoso (2012) yang menyatakan bahwa perceived ease of use berpengaruh terhadap attitude toward using. Sementara itu, penelitian yang dilakukan oleh Chan dan Lu (2004) menyatakan bahwa perceived ease of use berpengaruh terhadap perceived usefulness.

Penelitian terdahulu yang dilakukan oleh Nysveen (2005) memberikan informasi bahwa faktor yang mendukung munculnya behavioral intention adalah perceived usefulness. Penelitian yang dilakukan oleh Dewa (2018) menjelaskan bahwa visibility berpengaruh terhadap attitude toward using. Dilain pihak attitude toward using juga dipengaruhi oleh enjoyment (Santoso, 2012) dan social influence (Taylor dan Todd, 195). Attitude toward using berpengaruh langsung terhadap behavioral intention (Weng et al. 2018). Hingga pada akhirnya behavioral intention berpengaruh terhadap Actual usage (Chau, 2010).

\section{HASIL}

\section{Karakter Responden}

Karakteristik responden menggambarkan keberagaman responden yang mewakili segmentasi nasabah Bank XYZ yang telah menggunakan internet banking. Berdasarkan karakteristik nasabah tersebut, maka bisa didapatkan informasi yang dapat dijadikan masukan bagi management. Sebaran karakteristik responden ditampilkan pada Tabel 2. 


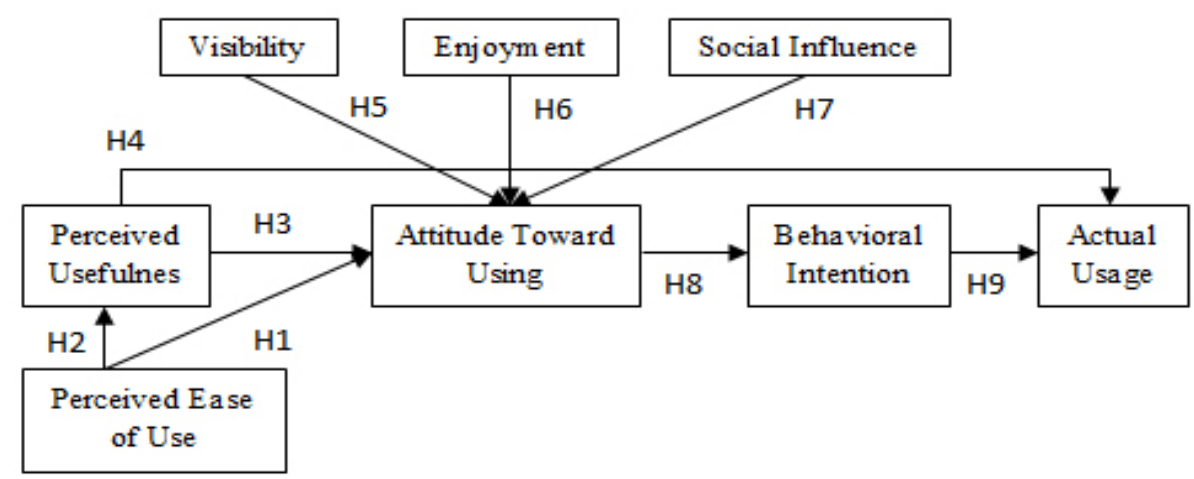

Gambar 1. Kerangka pemikiran penelitian

Tabel 2. Karakteristik responden

\begin{tabular}{lcclcc}
\hline Karakteristik & $\mathrm{n}$ & $\%$ & Karakteristik & $\mathrm{n}$ & $\%$ \\
\hline Jenis kelamin & & & Pekerjaan & & \\
Laki-laki & 56 & 43,1 & Tidak bekerja & 2 & 1,5 \\
Perempuan & 74 & 56,9 & Pelajar/ Mahasiswa & 1 & 0,8 \\
Usia & & & Pegawai negeri & 4 & 3,1 \\
$18 \leq \mathrm{X} \leq 25$ tahun & 17 & 13,1 & Pegawai swasta & 106 & 81,5 \\
$26 \leq \mathrm{X} \leq 35$ tahun & 81 & 62,3 & Profesional & 4 & 3,1 \\
$36 \leq \mathrm{X} \leq 45$ tahun & 26 & 20,0 & Wirausaha & 11 & 8,5 \\
X $>5$ tahun & 6 & 4,6 & Lainnya & 2 & 1,5 \\
Pendidikan & & & Pendapatan (per bulan) & & \\
SMA & 2 & 1,5 & $\leq$ Rp. 1 juta & 1 & 0,8 \\
Diploma & 3 & 2,3 & Rp1 juta $<$ X $\leq$ Rp5 juta & 12 & 9,2 \\
Sarjana (S1) & 115 & 88,5 & Rp5 juta $<$ X $\leq$ Rp10 juta & 45 & 34,6 \\
Pascasarjana (S2) & 9 & 6,9 & X $>$ Rp10 juta & 72 & 55,4 \\
Doktor (S3) & 1 & 0,8 & & & \\
\hline
\end{tabular}

Dari total 130 responden, lebih dari setengah responden berjenis kelamin perempuan. Usia responden sebagian besar berada pada usia produktif, yaitu antara 26 tahun sampai dengan 35 tahun dan hampir seluruh responden memiliki latar belakang pendidikan sarjana. Pekerjaan yang dimiliki oleh reponden sebagian besar sebagai pegawai swasta dan lebih dari setengahnya memiliki pendapatan perbulan diatas Rp10 juta.

\section{Uji Kecocokan Model Pengukuran (Measurement Model Fit)}

Uji kecocokan model diperlukan untuk menggetahui bahwa model yang digunakan dalam penelitian telah sesuai. Agar dapat dikatakan bahwa model yang digunakan sudah tepat, ada kriteria yang harus dipenuhi. Suatu variabel indikator dikatakan baik apabila memiliki nilai loading factor $\geq 0,5$. Tabel 3 menjelaskan mengenai nilai loading factor pada setiap indikator.
Variabel perceived usefulness sebagian besar dikontribusikan oleh indikator efisiensi (X1) dengan nilai loading factor sebesar 0,81 karena nasabah akan memperhatikan seberapa efisien internet banking terhadap penggunaan. Untuk variabel perceived ease of use kontribusi terbesar berasar didapat dari indikator kemudahan bertransaksi (X5) dengan nilai loading factor sebesar 0,90. Pada variabel visibility indikator yang paling besar berkontribusi adalah bagaimana intenet banking terlihat digunakan oleh teman (X7), semakin sering internet banking terlihat digunakan oleh teman maka akan semakin berpengaruh terhadap sikap penggunaan. Indikator bagaimana proses menggunakan Internet banking menjadi menyenangkan (X11) memberikan kontribusi yang sangat besar (nilai loading factor sebesar 0,89) terhadap variabel Enjoyment. Hal tersebut menjelaskan bahwa apabila nasabah telah merasa nyaman terhadap proses penggunaan maka akan semakin baik sikap penggunaan terhadap internet 
banking. Indikator yang menyatakan bahwa penggunaan internet banking karena teman (X14) memberikan kontribusi yang paling besar (nilai loading factor sebesar 0,91 ) pada variabel social influence. Indikator suka dengan ide menggunakan internet banking untuk mentrasfer dana (X17) berkontribusi paling besar terhadap variabel attitude toward using (nilai factor loading sebesar 0,82). Penggunaan internet banking masih identik dengan fungsi untuk mentransfer dana. Untuk variabel behavior intention indikator yang paling berkontribusi adalah keinginan untuk menggunakan internet banking dimasa mendatang (X21) dengan nilai loading factor sebesar 0,89. Variabel actual usage paling banyak mendapat kontribusi dari indikator tindakan menggunakan internet banking untuk mentransfer dana/ pembayaran e-commerce/ bayar listrik/ membeli tiket/ membeli pulsa/ transaksi finansial lainnya. Pengukuran validitas diharapkan dapat memberikan model yang fit. Dari hasil pengolahan data menggunakan Lisrel, fit model yang diperoleh adalah seperti pada Tabel 4 .

\section{Pengujian Hipotesis}

Penggunaan internet banking (actual usage) dipengaruhi oleh variabel lain, baik secara langsung dan tidak langsung. Actual usage secara langsung dipengaruhi oleh behavioral intention dan secara tidak langsung dipengaruhi oleh perceived ease of use, visibility, enjoyment, dan social influence melalui variabel perceived usefulness, attitude toward using dan behavioral intention. Pengujian hipotesis pada penelitian ini melalui pengujian koefisien jalur pada model persamaan struktural. Tabel 5 menjelaskan hasil estimasi perhitungan model SEM dengan menggunakan software Lisrel 8.5.1. Apabila nilai path coefficient $\geq 0,05$ dan nilai t-hitung $>1.96$ maka dapat dikatakan bahwa pengaruh variabel tersebut signifikan.

Tabel 5 menjelasakan bagaimana pengaruh langsung antar variabel. Variabel yang secara langsung memengaruhi attitude toward using diantaranya adalah perceived ease of use, perceived usefulness, visibility, enjoyment, dan social influence. Pengaruh antar variabel lainnya yaitu, perceived usefulness dipengaruh langsung oleh perceived ease of use. Selanjutnya, variabel behavioral intention dipengaruhi langsung oleh perceived usefulness dan attitude toward using. Pada Tabel 5 juga menjelaskan pengaruh antar variabel yang signikan dan tidak signifikan.
Perceived ease of use merupakan sebuah persepsi akan kemudahan dalam menggunakan. Apabila sebuah aplikasi yang diperkenalkan dianggap memiliki persepsi bahwa mudah untuk digunakan maka diharapkan akan berdampak pada sikap untuk menggunakan aplikasi tersebut. Hal ini yang diharapan akan terjadi pada aplikasi internet banking Bank XYZ. Nasabah memiliki persepsi bahwa internet banking Bank XYZ dapat dengan mudah digunakan untuk transaksi finansial sehingga nasabah Bank XYZ dapat langsung bersikap untuk menggunakan internet banking. Akan tetapi berdasarkan hasil penelitian yang didapat, persepsi akan kemudahan untuk menggunakan internet banking tidak berpengaruh terhadap sikap menggunakan internet banking (tolak H1). Hal tersebut bertolak belakang dengan hasil penelitian yang dilakukan oleh Adhiputra (2015), Santoso (2012), yang menyatakan bahwa variabel perceived ease of use berpengaruh positif terhadap sikap.

Tabel 3. Nilai Loading Factor dan T-hitung

\begin{tabular}{lcccc}
\hline Variabel & & Loading Factor & T-Hit & Ket. \\
\hline Perceived & $\mathrm{X} 1$ & 0,81 & - & Valid \\
usefulness & $\mathrm{X} 2$ & 0,70 & 8,52 & Valid \\
& $\mathrm{X} 3$ & 0,73 & 8,98 & Valid \\
Perceived & $\mathrm{X} 4$ & 0,78 & 10,32 & Valid \\
ease of use & $\mathrm{X} 5$ & 0,90 & 12,98 & Valid \\
& $\mathrm{X} 6$ & 0,78 & 10,42 & Valid \\
Visibility & $\mathrm{X} 7$ & 0,83 & 9,95 & Valid \\
& $\mathrm{X} 8$ & 0,73 & 8,47 & Valid \\
& $\mathrm{X} 9$ & 0,56 & 6,08 & Valid \\
Enjoyment & $\mathrm{X} 10$ & 0,74 & 9,69 & Valid \\
& $\mathrm{X} 11$ & 0,89 & 12,72 & Valid \\
& $\mathrm{X} 12$ & 0,88 & 12,38 & Valid \\
Social & $\mathrm{X} 13$ & 0,79 & 10,36 & Valid \\
influence & $\mathrm{X} 14$ & 0,91 & 12,77 & Valid \\
& $\mathrm{X} 15$ & 0,81 & 10,79 & Valid \\
Attitude & $\mathrm{X} 16$ & 0,75 & - & Valid \\
toward & $\mathrm{X} 17$ & 0,82 & 10,86 & Valid \\
using & $\mathrm{X} 18$ & 0,76 & 8,70 & Valid \\
& $\mathrm{X} 19$ & 0,64 & 7,31 & Valid \\
& $\mathrm{X} 20$ & 0,83 & 9,89 & Valid \\
Behavioral & $\mathrm{X} 21$ & 0,89 & - & Valid \\
intention & $\mathrm{X} 22$ & 0,88 & 14,09 & Valid \\
Actual & $\mathrm{Y} 1$ & 0,76 & - & Valid \\
Usage & $\mathrm{Y} 2$ & 0,71 & 8,32 & Valid \\
& $\mathrm{Y} 3$ & 0,60 & 6,96 & Valid \\
& $\mathrm{Y} 4$ & 0,82 & 9,65 & Valid \\
\hline
\end{tabular}


Persepsi kemudahan untuk menggunakan tidak berpengaruh langsung terhadap sikap menggunakan internet banking, melainkan persepsi kemudahan penggunaan berpengaruh positif terhadap persepsi terhadap persepsi kegunaan. Hal tersebut sesuai dengan hasil penelitian yang dilakukan oleh Chan dan $\mathrm{Lu}$ (2004) mengenai perilaku penggunaan internet banking di Hongkong, hasil penelian yakni variabel perceived ease of use berpengaruh signifikan terhadap perceived usefulness. Nasabah yang meyakini persepsi bahwa internet banking Bank XYZ mudah untuk digunakan memengaruhi keyakinan nasabah bahwa intrnet banking Bank XYZ memiliki manfaat bagi nya. Sebelum nasabah merasakan kegunaan dari internet banking Bank XYZ, nasabah harus merasa yakin bahwa cara menggunakan internet banking untuk transaksi finansial itu mudah. Pengukuran dari persepsi kemudahan penggunaan internet banking adalah kemudahan dalam prosedur, tata cara penggunaan serta keyakinan kemudahan internet banking. Prosedur yang harus dilalui oleh nasabah agar dapat menggunakan internet banking Bank XYZ yaitu dengan mengisi form pendaftaran pada cabang terdekat dan setelah didaftarkan nasabah langsung dapat menggunakan internet banking Bank XYZ. Untuk bertransaksi dengan internet banking nasabah harus menggunakan token yang telah didaftarkan oleh petugas customer service officer dan kemudian melalui token tersebut nasabah akan mendapatkan kode rahasia yang harus di masukan pada saat menggunakan internet banking Bank XYZ untuk keamanan nasabah. Dengan prosedur yang mudah dan juga alat transaksi yang tidak rumit, nasabah akan menganggap menggunakan internet banking Bank XYZ menjadi mudah (terima H2).

Tabel 4. Nilai goodness of fit

\begin{tabular}{lc}
\hline Kriteria & Nilai \\
\hline Chi-square & 315,08 \\
Non-Centrality Parameters (NCP) & 71,96 \\
Goodness-of-fit (GFI) & 0,85 \\
Root Mean Square Residual (RMR) & 0,046 \\
Rot Mean Square Error Approximation & 0,049 \\
(RMSEA) & \\
Expected Cross Validation Index (ECVI) & 4,19 \\
\hline
\end{tabular}

Variabel visibility terdiri dari tiga indikator, yaitu internet banking terlihat digunakan oleh teman responden, internet banking terlihat digunakan oleh orang lain, dan internet banking terlihat digunakan di tempat umum. Dari ketiga idikator tersebut yang memberikan kondtribusi terbesar adalah internet banking terlihat digunakan oleh teman responden. Teman memberikan pengaruh yang sangat kuat karena teman merupakan salah satu wadah untuk mempromosikan internet banking. Teman adalah orang yang lebih sering ditemui dan memiliki ikatan secara emosional sehingga apabila teman responden sering terlihat menggunakan internet banking untuk transakasi finansial maka akan memengaruhi responden untuk melakukan hal yang 
sama (terima H5). Dengan demikian maka visibility berpengaruh positif terhadap sikap. Hal tersebut sesuai dengan hasil penelitian yang telah dilakukan oleh Dewa (2018).

Variabel enjoyment memiliki tiga indikator pengukuran, yaitu senang menggunakan internet banking, proses internet banking menyenangkan, dan rasa senang yang ditimbulkan pada saat menggunakan internet banking. Dari ketiga indikator tersebut, indikator yang menyatakan bahwa proses menggunakan internet banking menyenangkan memberikan kontribusi terbesar terhadap variabel enjoyment. Hal tersebut menjelaska bahwa proses menggunakan internet banking Bank XYZ tidak menyulitkan penggunanya sehingga pengguna senang dan nyaman untuk menggunakan internet banking. Rasa senang dan kenyamanan tersebut menimbulkan sikap untuk menggunakan internet banking untuk bertransaksi finansial (terima H6). Hasil penelitian sesuai dengan penelitian yang dilakukan oleh Santoso (2012) yang menyatakan bahwa enjoyment berpegaruh signifikan terhadap sikap.

Indikator yang paling berkontribusi terhadap variabel social influence adalah teman. Walaupun demikian berdasarkan hasil penelitian teman dan indikator lainnya tidak memberikan pengaruh yang signifikan terhadap sikap penggunaan internet banking. Bagaimana cara teman dan keluarga memberikan pengaruh terhadap pengguna yaitu seperti menceritakan bagaimana pengalaman mereka menggunakan internet banking Bank XYZ atau pun hanya dengan memberikan informasi mengenai internet banking Bank XYZ. Dengan demikian cara tersebut tidak cukup memengaruhi nasabah untuk menggunakan internet banking. Diperlukan faktor lain agar nasabah menggunakan internet banking (tolak H7). Dengan demikian maka social influence tidak berpengaruh terhadap sikap dan hal tersebut bertolak belakang dengan hasil penelitian yang dilakukan oleh Kurnia (2006).

Pengukuran terhadap attitude toward using memiliki lima indikator. Keyakinan mengenai manfaat internet banking memberikan kontribusi terbesar kepada sikap penggunaan internet banking. Manfaat yang akan didapat, mendorong pengguna untuk menggunakan internet banking karena tujuan dari pengenalan internet banking kepada nasabah adalah agar nasabah merasa nyaman dan dapat membantu transaksi nasabah.
Dengan demikian maka manfaat yang telah didapat oleh nasabah memicu sikap untuk menggunakan internet banking (terima H8). Hal tersebut sesuai dengan hasil penelitian yang dilakukan oleh Weng et al. (2018), Shabrina et al. (2018) dan Setiawati et al. (2018), meskipun bertentangan dengan studi Nugroho et al. (2018).

Behavioral intention terdiri dari dua indikator. Dari kedua indikator, minat untuk menggunakan kembali internet banking dimasa mendatang memiliki kontribusi yang lebih besar. Aplikasi internet banking diharapkan dapat menjadi solusi bagi nasabah, pengalaman baik dalam menggunakan internet banking membuat nasabah ingin menggunakan kembali înternet banking sehingga terbentuk sebuah ketergantungan oleh nasabah untuk terus menggunakan internet banking dimasa mendatang (terima H9). Dengan demikian variabel behavioral intention berpengaruh terhadap actual usage yang didukung dari penelitian yang dilakukan oleh Chau (2010) dan Phuan et al. (2011).

\section{Pengaruh tidak langsung terhadap penggunaan internet banking}

Pengaruh tidak langsung pengunaan internet banking dipengaruhi oleh variabel perceived ease of use, visibility, enjoyment, dan social influence. Penggunaan internet banking $69 \%$ dipengaruhi secara langsung oleh variabel perceived ease of use, visibility, enjoyment, dan social influence. Berdasarkan hasil penelitian terdapat dua variabel yang berpengaruh signifikan terhadap penggunaan internet banking, yaitu variabel visibility dan enjoyment. Bagaimana keempat varibel tersebut memengaruhi penggunan internet banking dapat dijelaskan melalui Tabel 6.

Variabel perceived ease of use secara tidak langsung memberikan kontribusi yang tidak signifikan terhadap penggunaan internet banking dengan melihat nilai path coefficient sebesar $-0,03$ atau kurang dari 0,05 dan dengan nilai t-hitung sebesar $-0,18$ atau kurang dari 1,96. Dengan demikian maka persepsi terhadap kemudahan penggunaan internet banking yang telah dirasakan oleh pengguna internet banking tidak memengaruhi penggunaan kembali internet banking karena yang lebih dibutuhkan oleh nasabah untuk menggunakan internet banking adalah seperti manfaat yang diperoleh. 
Variabel visibility secara tidak langsung memengaruhi penggunaan internet banking melalui variabel attitude toward using dan variabel behavioral intention. Hal tersebut dapat terlihat dari nilai path coefficient sebesar 0,21 atau lebih besar dari 0,05 dan dengan nilai t-hitung sebesar 2,52 atau lebih besar dari 1,96. Dengan demikian maka dapat disimpulan bahwa semakin sering internet banking terlihat digunakan oleh orang lain seperti teman dan keluarga akan membuat pengguna internet banking mau dan akan menggunakan kembali internet banking.

Variabel enjoyment secara tidak langsung memengaruhi penggunaan internet banking melalui variabel attitude toward using dan behavioral intention. Hal tersebut dapat terlihat dari nilai path coefficient sebesar 0,69 atau lebih besar dari 0,05 dan nilai t-hittung sebesar 3,70 atau lebih besar dari 1,96. Perasaan senang pada saat menggunakan internet banking memengaruhi sikap penggunaan internet banking dan kemudian memengaruhi minat untuk menggunakan kembali hingga pada akhirnya nasabah menggunakan kembali internet banking.

Variabel social influence secara tidak langsung berpengaruh tidak signifikan terhadap penggunaan internet banking melalui variabel attitude toward using dan behavioral intention. Hal tersebut terlihat pada nilai path coefficient sebesar 0,043 atau kurang dari 0,05 dan nilai t-hitung sebesar 0,86 atau kurang dari 1,96 . Hal tersebut menjelaskan bahwa walaupun teman dan keluarga telah menggunakan internet banking tidak memengaruhi sikap penggunaan internet banking dan tidak menimbulkann minat untuk menggunakan kembali hingga sehingga tidak memberikan kontribusi terhadap penggunaan kembali internet banking.

\section{Implikasi Manajerial}

Implikasi manajerial dari hasil penelitian diterapkan dalam bentuk segmentation, targetting, dan positioning (STP). Segmentation pada aspek geografis, manajemen dapat memfokuskan untuk meningkatkan pengenalan mengenaiinternetbankingpadanasabahdiareaperkantor. Manajemen dapat fokus untuk menarik nasabah baru khususnya dengan pekerjaan karyawan swasta untuk membuka account dan kemudian dapat menawarkan penggunaan internet banking. Aspek demografis dapat dilihat dari usia pengguna internet banking. Pengguna internet banking Bank XYZ didominasi oleh pengguna pada usia produktif dan manajemen dapat membidik rentang usia tersebut. Pada aspek psikologi, manajemen dapat fokus untuk mendekati nasabah dengan latar belakang pendidikan. Mayoritas responden memiliki latar belakan pendidikan sarjana. Manajemen dapat mempertimbangkan untuk mulai memperkenalkan internet banking kepada mahasiswa untuk mentrasfer dana atau pun untuk e-commerce. Perilaku penggunaan internet banking dapat menjadi fokus manajemen untuk lebih memasarkan kegunaan dari internet banking karena fitur seperti pembayaran listrik serta pembayaran e-commerce masih sedikit.

Tabel 5. Pengaruh langsung antar variabel

\begin{tabular}{|c|c|c|c|c|}
\hline & Pengaruh Variabel & Path coefficient & T-hitung & Simpulan \\
\hline H1 & Perceived ease of use $\rightarrow$ Attitude toward using & $-0,95$ & $-1,39$ & Tidak signifikan \\
\hline $\mathrm{H} 2$ & Perceived ease of use $\rightarrow$ Perceived usefulness & 0,96 & $10,26^{*}$ & Signifikan \\
\hline $\mathrm{H} 3$ & Perceived usefulness $\rightarrow$ Attitude toward using & 0,74 & 1,15 & Tidak signifikan \\
\hline $\mathrm{H} 4$ & Perceived usefulness $\rightarrow$ Behavioral intention & 0,17 & $2,06^{*}$ & Signifikan \\
\hline H5 & Visibility $\rightarrow$ Attitude toward using & 0,27 & $2,59 *$ & Signifikan \\
\hline H6 & Enjoyment $\rightarrow$ Attitude toward using & 0,91 & $3,87 *$ & Signifikan \\
\hline $\mathrm{H} 7$ & Social influence $\rightarrow$ Attitude toward using & 0,06 & 0,86 & Tidak signifikan \\
\hline H8 & Attitude toward using $\rightarrow$ Behavioral intention & 0,79 & $7,04 *$ & Signifikan \\
\hline H9 & Behavioral intention $\rightarrow$ Actual usage & 0,96 & $10,20 *$ & Signifikan \\
\hline
\end{tabular}

Ket : * signifikan pada t-hitung $\geq 1.96$

Tabel 6. Pengaruh tidak langsung penggunaan internet banking

\begin{tabular}{|c|c|c|c|c|}
\hline Pengaruh tidak langsung & Path cefficient & T-Hit & R-square & Keterangan \\
\hline Perceived ease of use $\rightarrow$ Actual usage & $-0,03$ & $-0,18$ & 0,69 & Tidak signifikan \\
\hline Visibility $\rightarrow$ Actual usage & 0,21 & 2,25 & & Signifikan \\
\hline Enjoyment $\rightarrow$ Actual usage & 0,69 & 3,70 & & Signifikan \\
\hline Sosial influence $\rightarrow$ Actual usage & 0,04 & 0,860 & & Tidak signifikan \\
\hline
\end{tabular}


Targeting nasabah adalah nasabah yang belum menggunakan dan juga yang telah menggunakan internet banking selama kurang dari enam bulan. Tujuan dari membidik target tersebut untuk menggunakan serta meningkatkan penggunaan kembali internet banking. Nasabah yang telah menggunakan internet banking kurang dari enam bulan harus tetap diinformasihkan kembali mengenai fitur transaksional yang dapat dilakukan melalui internet banking sehingga mereka akan terbiasa bertransaksi dengan menggunakan internet banking. Positioning produk internet banking Bank XYZ adalah menjadi bank pertama yang memperkenalkan internet banking secara masal di Indonesia, sehingga fitur-fitur yang terdapat pada internet banking Bank XYZ harus selalu berkembang dan inovatif.

\section{KESIMPULAN DAN SARAN}

\section{Kesimpulan}

Perceived ease of use secara langsung berpengaruh signifikan terhadap perceived usefulness. Semakin mudah proses dan cara penggunaan internet banking maka akan membuat nasabah merasakan manfaat dari menggunakan internet banking. Akan tetapi perceived ease of use secara tidak langsung tidak memengaruhi penggunaan kembali internet banking karena yang dibutuhkan oleh nasabah agar mau menggunakan kembali internet banking adalah merasakan manfaat yang telah diperoleh.

Behavioral intention berpengaruh langsung dan signifikan terhadap penggunaan kembali internet banking (actual usage). Minat menjadi penentu terhadap penggunaan kembali internet banking sehingga sebelum nabah menggunakan kembali internet banking, nasabah harus memiliki minat untuk menggunakan kembali terlebih dahulu hingga pada akhirnya bertindak untuk menggunakan kembali internet banking. Attitude toward using berpengaruh langsung dan signifikan terhadap behavioral intention. Sikap penggunaan internet banking menjadi salah satu faktor yang memengaruhi timbulnya minat untuk menggunakan kembali internet banking. Oleh karena itu, sikap penggunaan internet banking harus ditingkatkan agar minat untuk menggunakan kembali internet banking semakin besar. Semakin banyak manfaat yang dirasakan oleh nasabah dalam menggunakan internet banking, maka akan semakin besar minat yang ditibulkan.
Perceived usefulness secara langsung berpengaruh signifikan terhadap behavioral intention. Semakin banyak manfaat yang didapat oleh nasabah dalam menggunakan internetbankingmaka akanmemengaruhi minat pengguna untuk menggunakan kembali internet banking. Visibility berpengaruh signifikan terhadap attitude toward using dan secara tidak langsung memberikan pengaruh terhadap penggunaan kembali internet banking. Semakin sering internet banking terlihat oleh nasabah maka akan memengaruhi sikap pengguna sehingga menimbulkan minat untuk menggunakan kembali hingga pada akhirnya nasabah menggunakan kembali internet banking. Enjoyment secara langsung berpengaruh signifikan terhadap attitude toward using dan secara tidak langsung memengaruhi minat untuk menggunakan kembali internet banking serta penggunaan kembali internet banking. Jika nasabah merasa senang serta nyaman pada saat menggunakan internet banking maka akan memengaruhi sikap pengguna.

\section{Saran}

Peneliti memiliki keterbatasan dalam mengetahui secara rinci jumlah populasi dan responden berasal dari wilayah tertentu. Untuk penelitian selanjutnya dengan tema yang sama, perlu diperhatikan beberapa saran. Saran yang pertama yakni, untuk penelitian selanjutnya dapat menambahkan variabel lain nya yang memengaruhi behavioral intention seperti menambahkan variabel cost. Saran penelitian selanjutnya dapat melakukan pengembangan terhadap faktor yang berpengarul langsung terhadap actual usage internet banking, seperti manambahkan faktor trust.

\section{DAFTAR PUSTAKA}

Aaker DA, Keller KL. 1990. Customer evaluations of brand extensions. Journal of Marketing 1(54): 27-41. https://doi. org/10.1177/002224299005400102.

Adhiputra MW. 2015. Aplikasi technology acceptance model terhadap pengguna layanan internet banking. Jurnal Bisnis dan Komunikasi 2(1):5263.

Aditya R, Wardana A. 2016. Pengaruh perceived usefulness dan perceived ease of use terhadap behavioral intention dengan pendekatan 
technology acceptance model (TAM) pada pengguna instant messaging Line di Indonesia. Journal Siasat Bisnis 20(1): 24-32. https://doi. org/10.20885/jsb.vol20.iss1.art3.

Chan S, Lu M. 2004. Understanding internet banking adoption and use behaviour: A Hongkong perspective. Journal of Global Information Management 12(3): 21-43. https://doi. org/10.4018/jgim.2004070102.

Chau VSC, Ngai LWLC. 2010. The youth market for internet banking services: perceptions, attitude and behaviour. Journal of Services Marketing 24(1): 42-60. https://doi. org/10.1108/08876041011017880.

Dewa CB. 2018. Pengaruh celebrity endorser terhadap keputusan pembelian wisatawan Yogyakarta pada produk oleh-oleh Jogja Scrummy. Jurnal Manajemen 8(1):1-9.

Gerrard P, Cunningham JB. 2003. The diffusion of internet banking among Singapore customers. International Journal of Banking Marketing 21(1): 16-28. https://doi. org/10.1108/02652320310457776.

Kurnia S, Smith SP, Lee H. 2006. Consumers'perception of mobile internet in Australia. E-Business Review 5(1):19-32.

Lee E, Lee J. 2011. Customer adoption of internet banking: need-based and/or skill bassed. Marketing Management Journal.

Nysveen H, Pedersen PE, Thorbjornsen H. 2005. Intention to use mobile service: artecedent and cross-service comparisons. Journal of Academy of Marketing Science 33:330-346. https://doi. org/10.1177/0092070305276149.

Nugroho A, Najib M, Simanjuntak M. 2018. Factors affecting consumer interest in electronic money usage with theory of planned behavior (TPB). Journal of Consumer Sciences 3(1):15-27. https://doi.org/10.29244/jcs.3.1.15-27.

Parreno JM, Blas SS, Mafe CR, Manzano JA. 2013. Key factors of teenagers' mobile advertising acceptance. Industrial Management \& Data System 133(5):732-749. https://doi. org/10.1108/02635571311324179.
Phuan LP, Wong SL, Abu R. 2011. Factors influencing the behavioral intention to use the internet as a teaching-learning tool in home economics. Procedia-Social and Behavioral Sciences 59(2012): 180-187. https://doi.org/10.1016/j. sbspro.2012.09.263.

Poon WC. 2008. Users' adoption of e-banking services: the Malaysian perspectve. Journal of Business \& Industrial Marketing 23(1): 59-69. https://doi. org/10.1108/08858620810841498.

Santoso B. 2012. Pengaruh perceived usefulness, perceived ease of use, dan perceived enjoyment terhadap penerimaan teknologi informasi (studi empiris di Kabupaten Sragen). Jurnal Akutansi Indonesia 1(15):1-15.

Setiawati H, Hartoyo, Simanjuntak M. 2018. Analysis on intention of purchasing organic foods by the undergraduate students of IPB using the theory of planned behaviour approach. Journal of Management and Agribusiness 15 (2): 198-207. http://dx.doi.org/10.17358/jma.15.2.198.

Shabrina Z, Yuliati LN, Simanjuntak M. 2018. The effects of religiousity, pricing and corporate image on the attitude and the Intention to use sharia micro financing. Indonesian Journal of Business and Entrepreneurship 4(2):197-206. http://dx.doi.org/10.17358/ijbe.4.2.197.

Taylor S, Todd PA. 1995. Understanding information technology usage: a test of competing models. Information System Research 6(2): 85-188. https://doi.org/10.1287/isre.6.2.144.

Yudha HN, Isgiyarta J. 2015. Analisa pengaruh persepsi nasabah bank terhadap internet banking adoption (studi pada nasabah perbankan yang menggunakan internet banking di Kota Surakarta). Diponogoro Journal of Accounting 4(4): 1-15.

Weng F, Yang R, Ho H, Su H. 2018. A TAM-based study of the attitude towards use intention of multimedia among school teachers. Applied System Innovation 1(36): 1-9. https://doi. org/10.3390/asi1030036.

Zaithaml V, Bitner, Gremler. 2013. Service MarketingIntegrating Customer Focus Across The Firm. New York: McGraw Hill. 